\title{
El ferrocarril
}

\section{Valeria Quintana}

Cuando Porfirio Díaz asubió como presidente (o más bien dictador) de México, el país estaba separado. La gente de del sur no conocía a la gente del norte, los huecos entre las clases sociales eran enormes, y había mucha pobreza. Al final de la dictadura, todavía había mucha gente con escasos recursos, y la población aún no se conocía. Sin embargo, en 1910 estalló la Revolución mexicana, una guerra civil que cambió la sociedad de México completamente, desde la economía hasta las clases sociales y su cultura. Todos estos cambios sucedieron en parte porque no hubo lugar del país en el cual la vida de la gente no se viera de una manera afectada por la Revolución. Los elitistas pelearon contra las clases obreras, el norte se enfrentó al sur, constitucionalistas contra federales, y para el final de la Revolución, los mexicanos (ya sea para bien o para mal) ya no eran extraños.

En gran parte, esto se debe al protagonista de la Revolución mexicana, que, aunque no tuvo una voz propia, se le veía en todos los aspectos de la Revolución mexicana: el ferrocarril. Ya sea por su papel en facilitar el movimiento de ejércitos, armamento y recursos o por cómo mitigó el desplazamiento de refugiados que causó la Revolución mexicana, el ferrocarril evidencia cómo transformó al país, esto se nota en todas partes, no hace falta leer un libro o ver un documental. Es suficiente ver una película de la época de oro del cine mexicano, ojear un mapa de México de la era revolucionaria o ver una imagen. Irónicamente, este instrumento que utilizaron los caudillos y constitucionalistas para ganar la guerra fue construido por el mismo dictador que querían derrocar, Porfirio Díaz.

Aunque es cierto que Porfirio Díaz fue derrocado por ser un "César", no respetar los derechos civiles de los ciudadanos mexicanos, y dar precedencia a intereses económicos extranjeros, no se le puede negar el título de padre del México moderno. Cuando él ascendió al poder en México en 1876, las vías férreas de México eran escasas. En 1873 sólo había alrededor de $572 \mathrm{~km}$ de vías férreas. Durante su régimen, se desarrolló un sistema de ferrocarriles que se extendían por todo el país y, para 1910, había alrededor de 19, $000 \mathrm{~km}$, con un costo estimado de $\$ 2$ billones de dólares (ajustados para la década de 1950). Además de conectar al país, el dictador también fue responsable por impulsar el desarrollo de industrias de textiles, petróleo y agricultura comercial (Haber). Estos sucesos transforman a México por completo, como se puede observar contrastando el mapa número 1 con el número 2, y la diferencia de 22 años es drástica. De 1894 (aquí Díaz ya llevaba 18 años en el poder) a 1916, México pasa de ser un país desconectado a ser ya un 
país unido de norte a sur, de este a oeste. No había región de México que estuviera aislada gracias a los ferrocarriles.

El énfasis de la dictadura porfirista en invertir en la economía, el transporte, las ciencias, así como incentivar las inversiones extranjeras, era porque la dictadura tenía una filosofía liberal y positivista. Es decir, los "científicos" (el gabinete de Porfirio Díaz) querían separar a México de la barbarie, y crear una clase media (burguesía), que eventualmente sacaría a México de la pobreza y lo pondría a la par de los países europeos y de Norteamérica. En algunos aspectos, Porfirio Díaz sí logró su propósito, ya que una pequeña clase burguesa emergió y México estaba conectado y prosperando económicamente. Sin embargo, los productos que salieron de la prosperidad que trajo Díaz, fueron los que también le quitaron el poder. Esto fue lo que pasó con el abuso que sufría la gente que vivía en el campo, además de la represión de derechos y oportunidades negadas a la clase media (abogados, doctores, maestros y trabajadores), la cual estaba harta de Díaz.

En el momento en el que estalló la Revolución mexicana en 1910, los caudillos que la encabezaron, aprovecharon la facilidad de movilidad que los ferrocarriles les otorgaban. Dañaron líneas que los ejércitos federales usaban, interceptaban recursos y los usaban para mover sus ejércitos. Roy Hoard, un trabajador para una compañía norteamericana de vías, cuenta cómo durante la Revolución él estuvo bajo territorio villista en la población de Madera. Cuenta de sus interacciones con el caudillo Pancho Villa y cómo sus ejércitos saboteaban las líneas férreas para impedir el movimiento de los ejércitos federales (Hulse 33) y movía su gente por el país. En el lado de los federales, si se comparan los mapas 2 y 3 , se ve que la mayoría de los complejos militares del norte estaban situados cerca de líneas de ferrocarril (o del mar). Es evidente que las líneas férreas eran importantes para los dos lados de la guerra.

No obstante, los ferrocarriles no sólo eran herramientas militares. Los ferrocarriles fueron núcleos de lo que representaba la Revolución. En ellos viajaban mujeres, niños y hasta bandas para tocar corridos. Ahí se congregaban mexicanos que querían luchar por un nuevo gobierno. Las mujeres viajaban con soldados para ayudar, como se puede ver en la foto "Mexican Revolution", y también eran lugares para reagruparse y recuperarse. En la foto "Francisco Villa" se puede ver al ejército Villista y al caudillo descansando sobre el carro de un ferrocarril. En "Carrying the Wounded" se muestran revolucionarios ayudando a soldados heridos al lado de un ferrocarril.

Por todos estos motivos, se puede observar que el ferrocarril fue el detonador que desencadenó dos etapas importantes que formarán a México: su desarrollo económico y su Revolución. Irónicamente, sucede que Díaz, el responsable del desarrollo del ferrocarril, fue derrocado en gran parte por este mismo objeto. No queda más que llegar a la conclusión de que las imágenes y referencias históricas del ferrocarril junto a mexicanos muestran circunstancias que captan la esencia del porfiriato y la Revolución mexicana, o sea (para bien o para mal) al México de hoy. 


\section{Anexo}

Mapa 1: Ferrocarril Internacional Mexicano y sus conexiones, 1894 (American Bank Note Co.): Este mapa muestra las líneas de ferrocarril de México a finales del siglo XIX.

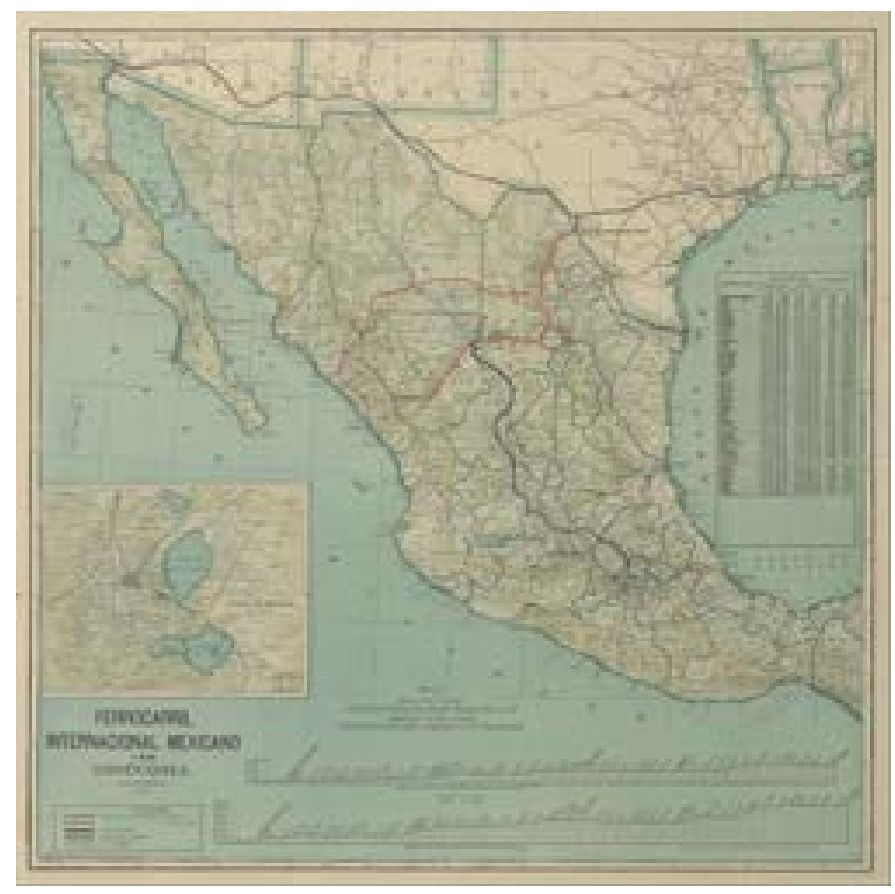

Mapa 2: Railroad map of México (US War Department): El mapa muestra al país en el año 1916, así como las vías de ferrocarril existentes y las propuestas.

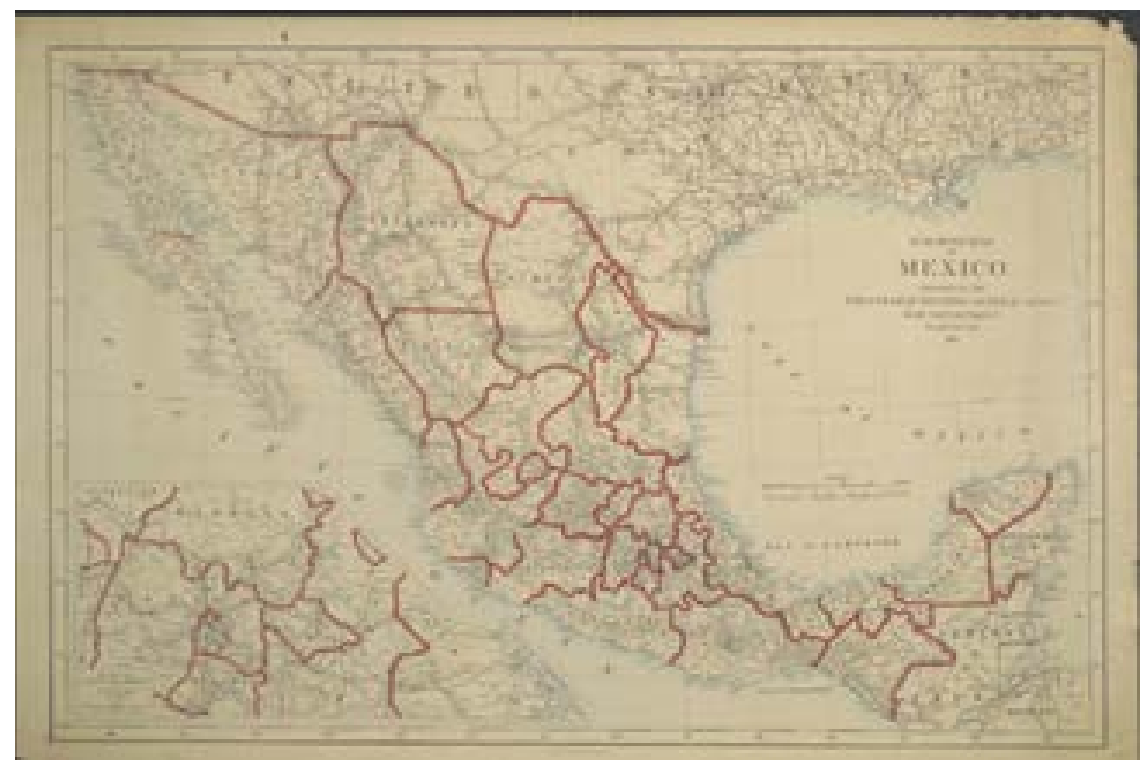


Mapa 3: The Mexican Situation: new comercial atlas map of México (Randy McNally). El mapa proviene del ejército norteamericano y es del año 1914. Muestra bases militares de los E.E.U.U durante la Revolución mexicana y los centros de comando del ejército federal. Además, señala en qué regiones de México tenían autoridad los caudillos.

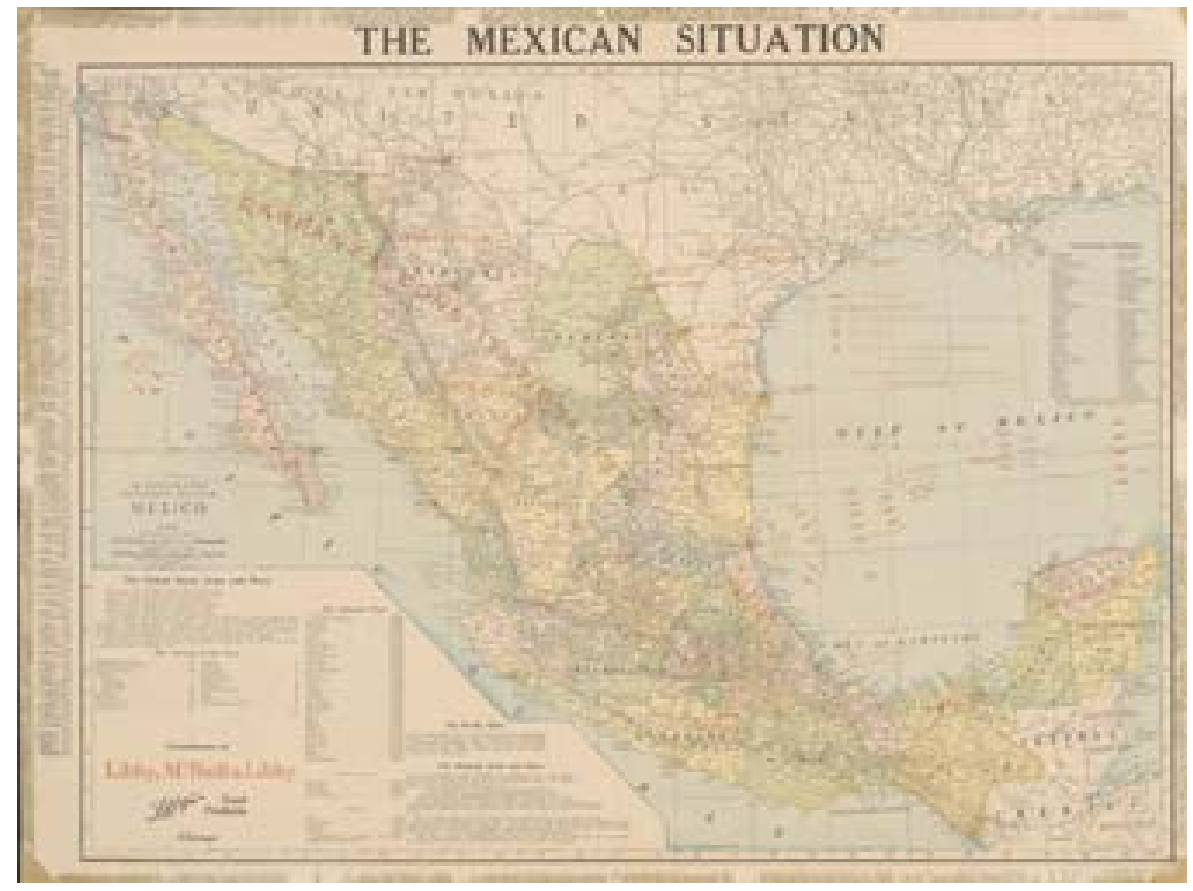

Figura 1: Es la clave del mapa "The Mexican Situation": Muestra las figuras y significado de símbolos.

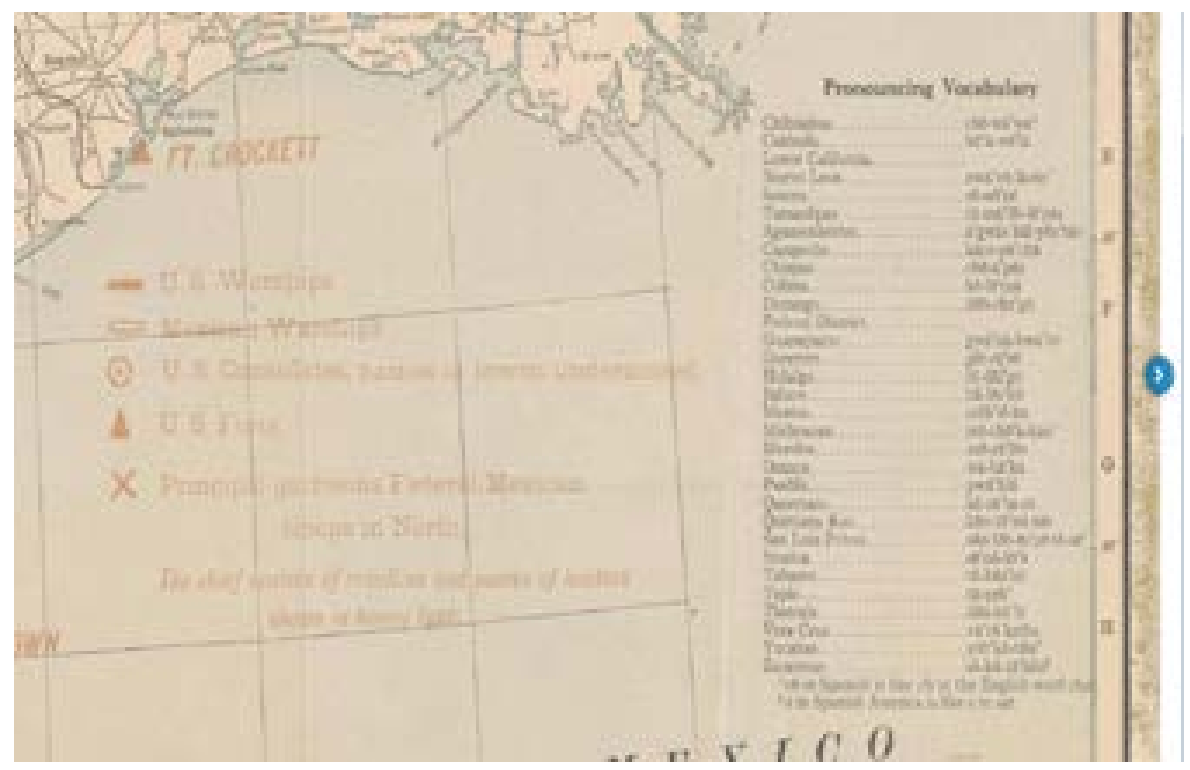


Derailed supply train (Otis): Tren de un ferrocarril descarrilado del lado del gobierno federal cargado de armamento y dinamita. A la derecha se pueden ver cuatro revolucionarios.

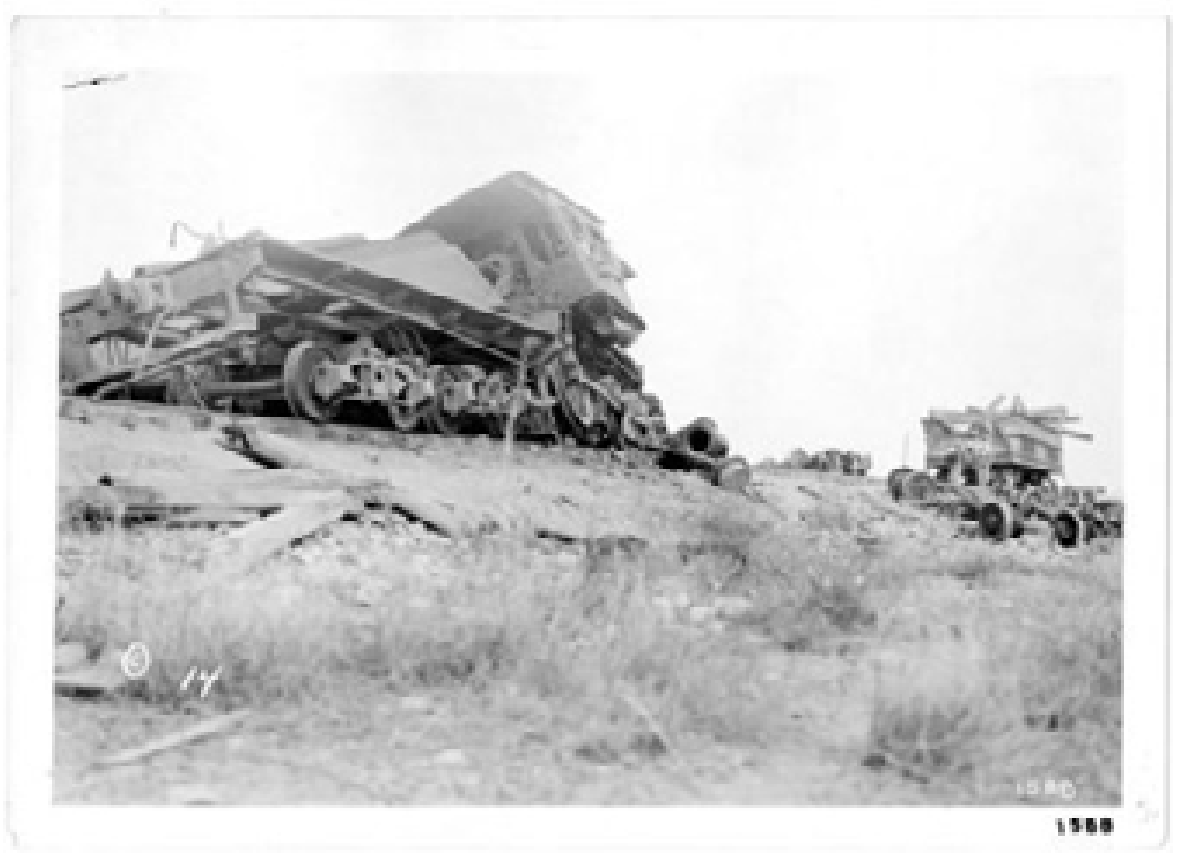

Francisco "Pancho" Villa (Otis): Pancho Villa, con un sombrero blanco, parado sobre un carro de ferrocarril y lo que parece ser una sonrisa. Descansando también sobre el tren hay villistas.

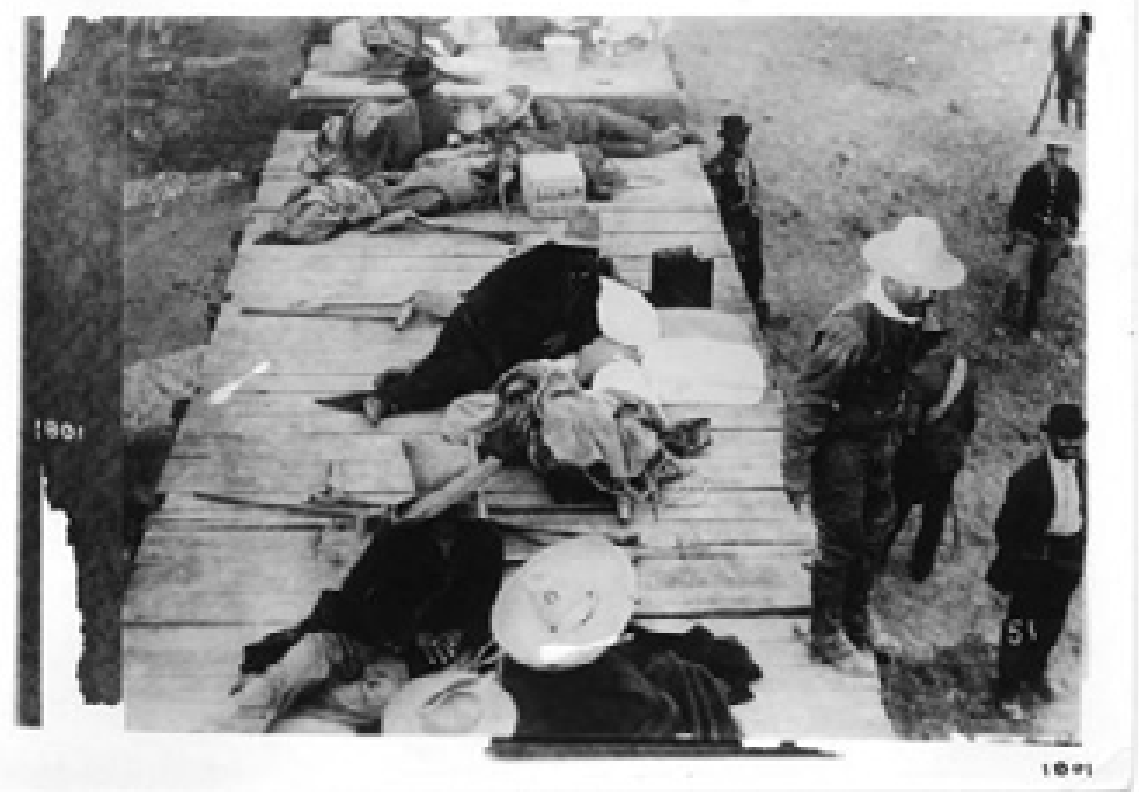


Mexican Revolution (Otis): Un ejército revolucionario, mujeres, niños y caballos. Arriba del ferrocarril se ven tablas de madera y carpas.

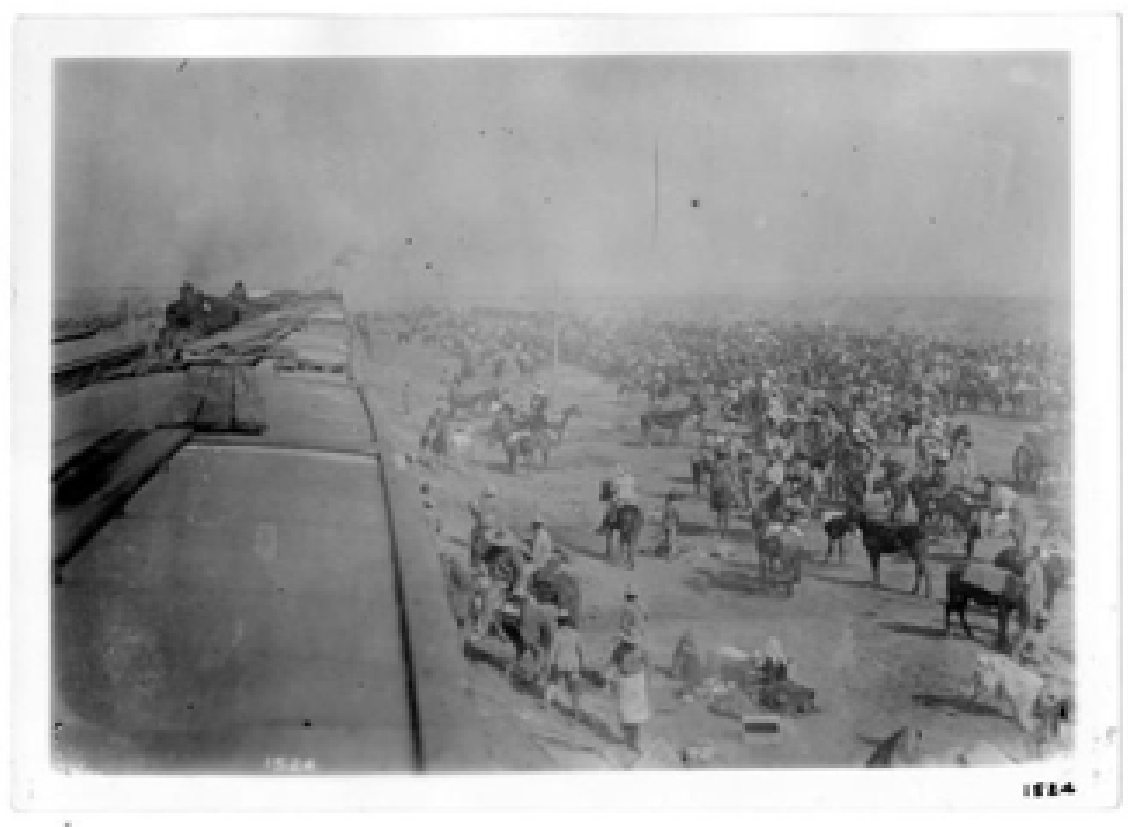

Carrying the Wounded (Otis): En la foto se ven revolucionarios cargando a un herido en una camilla, al lado de un ferrocarril. Junto a los soldados también se ven mujeres caminando a su lado.

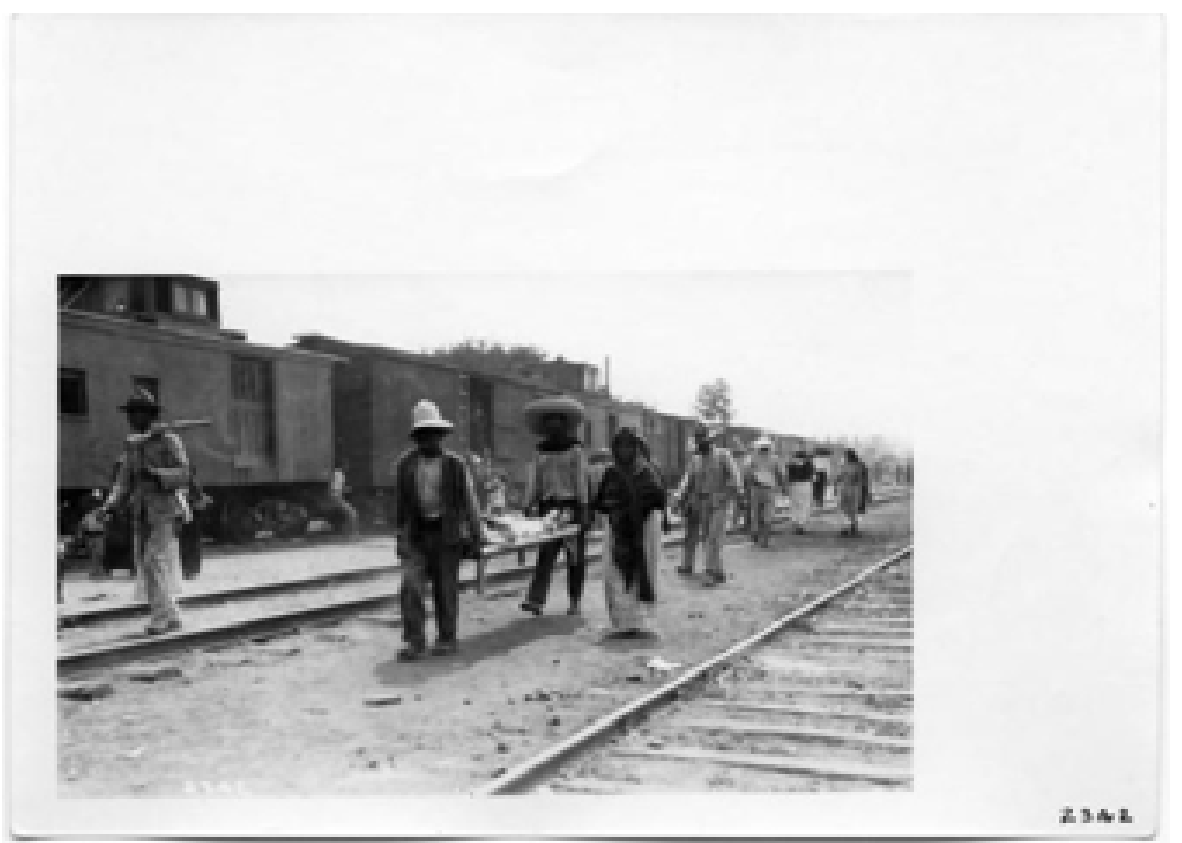




\section{Bibliografía}

American Bank Note Company. Ferrocarril Internacional Mexicano y sus conexiones. 1895. The Portal to Texas History, Denton. The University of North Texas at Denton, https://texashistory.unt.edu/ ark:/67531/metapth220359/?q=ferrocarril\%20internac ional\%20mexico\%20\#top. Accessed 19 Oct. 2016.

Aultman, Otis A. Carrying the Wounded. 1910-1920. The Portal to Texas History, Denton. The University of North Texas at Denton, texashistory.unt.edu/ark:/67531/metapth63449/. Accessed 17 Oct. 2016.

Aultman, Otis A. Derailed Supply Train. 1910-1920. The Portal to Texas History, Denton. The University of North Texas at Denton, texashistory.unt.edu/ark:/67531/metapth63230/. Accessed 17 Oct. 2016.

Aultman, Otis A. Francisco "Pancho" Villa. 1910-1920, The Portal to Texas History, Denton. The University of North Texas at Denton, texashistory.unt.edu/ark:/67531/metapth63275/. Accessed 17 Oct. 2016.

Aultman, Otis A. Mexican Revolution. 1910-1920. The Portal to Texas History, Denton. The University of North Texas at Denton, texashistory.unt.edu/ark:/67531/metapth63221/. Accessed 17 Oct. 2016.

Haber, Stephen H. "Assessing the Obstacles to Industrialisation: The Mexican Economy, 1830-1940". Journal of Latin American Studies 24.1 (1992): 1-32.

Hulse, J.F. Railroads \& Revolutions: The Story of Roy Hoard. Mangan Bokks: E1 Paso, 1986 Rand McNally and Company. The Mexican situation: new commercial atlas map of Mexico.

1914. The Portal to Texas History, Denton. The University of North Texas at Denton, https:// texashistory.unt.edu/ark:/67531/metapth231395/?q=mexico\%20revolution. Accessed 19 Oct. 2016.

Railroad map of Mexico. 1916. The Portal to Texas History, Denton. The University of North Texas at Denton, https://texashistory.unt.edu/ark:/67531/metapth220501/. Accessed 18 Oct. 2016. 